\title{
Inelastic Ultimate Load Analysis of Steel Frames Considering Lateral Torsional Buckling under Distributed Loads
}

\author{
Mutlu Secer $^{1 *}$, Ertugrul Turker Uzun ${ }^{2}$ \\ ${ }^{1}$ Department of Civil Engineering, Faculty of Engineering and Architecture, \\ Izmir Katip Celebi University, 35620, Izmir, Turkey \\ 2 Department of Civil Engineering, Faculty of Engineering, \\ Izmir Institute of Technology, 35433, Izmir, Turkey \\ *Corresponding author, e-mail: mutlu.secer@ikc.edu.tr
}

Received: 28 November 2018, Accepted: 25 June 2019, Published online: 22 August 2019

\begin{abstract}
Contemporary structural design approaches necessitates ways to determine realistic behavior of structures. For this purpose, inelastic ultimate load analysis methods are used widely since strength and stability of whole structure can be represented. In this study, a numerical method is proposed for determining inelastic ultimate load capacity of steel frames considering lateral torsional buckling behavior under distributed loads. In the analyses, inelastic material behavior, second-order effects and residual stresses of the structural frame system and its members are taken into account. Additionally, lateral torsional buckling behavior is considered in the analysis using finite difference method and it is used for determining the structural load carrying capacity of steel frames. Consequently, the problem associated with flexural capacity decreases due to lateral torsional buckling is precisely considered in the load increment steps of inelastic ultimate load analysis. In order to validate the proposed method, numerical examples from the literature are calculated considering the proposed method, AISC 360-16 design specification equations and approaches from the literature. Results of the numerical examples show that lateral torsional buckling is a key issue in determining structural load carrying capacity. Thus, proposed analysis method is shown to be an efficient and consistent tool for inelastic ultimate load analysis.
\end{abstract}

Keywords

inelastic ultimate load analysis, lateral torsional buckling, second-order effects, steel frame, moment modification factor

\section{Introduction}

Determining the realistic behavior of structures has gained importance from both structural safety and economic perspectives. Therefore, structural analysis methods based on determination of inelastic ultimate load capacities which have different limitations and features are generally used for these purposes [1] In inelastic ultimate load analysis of steel frames, strength and stability of the whole structure is represented in terms of applied loads and monitored displacements. Additionally, considering structural stability problems in nonlinear analysis improves the capability of structural analysis model [2]. Especially, lateral torsional buckling (LTB) in slender steel structures is one of the most important stability problems and it affects structural behavior of steel structures substantially [3]. Thus, many researchers examined LTB precisely for determining the structural stability considering several cases in recent years. In these studies; members with various end conditions [4] imperfections [5], and curved geometry [6] are discussed and influences on the member behavior are investigated. Also, numerical solution techniques such as energy methods [7], finite difference methods [8], finite-integral methods [9] and finite elements methods [10] are applied to evaluate LTB behavior on steel members. Besides, experimental studies [11] are performed to evaluate the accuracy of the numerical analysis methods and to evaluate LTB behavior for different materials and load conditions. However, most of these papers are focused on investigating LTB using one-member solutions and effects of LTB on the entire structural behavior are not focused in details. On the other hand, LTB effects in steel frames are generally neglected by assuming adequate lateral bracings in some studies [12] about inelastic ultimate load analysis. 
In this study, a numerical analysis method is proposed for considering degradation of the flexural strength and stiffness caused by the LTB of steel frames under uniformly distributed loads. Flexural capacity decreases due to LTB is precisely considered using finite difference method and it is reflected in the load increment steps of ultimate load analysis of steel frames. In structural analyses inelastic material behavior, residual stresses, and second-order effects of the structural system and its component members are considered. Numerical examples from the literature are evaluated considering the proposed method, approaches from the literature and AISC 360-16 [13] design specification equations for validating the outcomes. Numerical results show that LTB affects structural behavior significantly and the proposed method is adequate to determine the structural behavior precisely.

\section{Inelastic ultimate load analysis}

Inelastic behavior is generally considered using plastic hinges in which yielding is concentrated at a small zone modeled by flexible springs. In structural models, the spring stiffness is infinitely large when no yielding occurs and spring stiffness tends to zero when the plastic moment capacity is reached. Inelastic analysis provides the redistribution of internal forces due to yielding of structural members and this process can be considered by an inclusion of a flexible spring stiffness in the incremental equilibrium equations. In order to perform inelastic analysis, some assumptions are made in this paper. These are summarized as: the element is originally straight and prismatic, plane cross-sections remain plane after deformation, sections are doubly symmetric, yielding of the cross-section is governed by normal stress, the material model is elastic-perfectly plastic and local buckling is ignored. On the other hand, effect of the axial force on the flexural stiffness of a member and the influence of gravity loads on side-sway stiffness of the frame is considered with second-order analysis. Second-order effects cause reductions in stiffness and affect the distribution of internal forces in the structural system and for this reason it is included in the analysis steps.

\subsection{Second-order analysis}

The equations of equilibrium need to be formulated on the geometry of the deformed structure when steel structural members are subjected to axial force. For this reason, stability functions [14], geometric stiffness matrix methods [15] and moment amplification factors of $B_{1}$ and $B_{2}$ method [16] are generally used for second-order analysis. In this study, $B_{1}$ and $B_{2}$ method, which is described in AISC 360-16 [13], is used and it's equations are given in Eqs. (1-2)

$M_{r}=B_{1} M_{n t}+B_{2} M_{l t}$,

$P_{r}=P_{n t}+B_{2} P_{l t}$,

where $M_{l t}$ is the first-order moment due to lateral deformation of the structure, $M_{n t}$ is first-order moment with the structure restrained against lateral deformation, $M_{r}$ is required second-order flexural strength, $P_{r}$ is required axial compressive strength, $P_{l t}$ is first-order axial force due to lateral deformation of the structure, $P_{n t}$ is first-order axial force with the structure restrained against lateral deformation.

\subsection{Axial force and bending moment interaction equations}

The relationship between axial force and bending moment is determined using bilinear interaction equations. In this study, Eq. (3) and Eq. (4) given in AISC 360-16 [13] are used to show the interaction between axial force and bending moment for steel members.

$$
\begin{aligned}
& P / P_{y}+8 M / 9 M_{p}=1.0 \text { for } P / P_{y} \geq 0.2, \\
& P / 2 P_{y}+M / M_{p}=1.0 \text { for } P / P_{y}<0.2,
\end{aligned}
$$

where: $P$ is axial force, $M$ is the bending moment, $P_{y}$ is the squash load and $M p$ is the plastic moment capacity.

\subsection{Residual stress}

Gradual yielding effect due to residual stress along the length of members under axial loads between two plastic hinges is considered by Column Research Council tangent modulus concept. In this concept, elastic modulus $E$ is reduced for accounting the reduction of the elastic portion of the cross-section and this approach is also considered in many studies [17] and modern design codes [18] as given in Eqs. (5-6).

$$
\begin{aligned}
& E_{t}=1.0 E \text { for } P \leq 0.5 P_{y}, \\
& E_{t}=4 \frac{P}{P_{y}} E\left(1-\frac{P}{P_{y}}\right) \text { for } P>0.5 P_{y} .
\end{aligned}
$$

\section{Lateral Torsional Buckling behavior}

LTB is one of the major stability problems for members under flexure and various studies [19] show that it influences structural steel design directly. LTB is caused by additional deformation due to out-of-plane displacement 
and rotation, as well as bending behavior of steel structural members in their plane. For LTB type of failure, the critical moment, which is a function of lateral and torsional stiffness, under the applied load or moment should be reached. Critical moment is affected by the element lengths in which out-of-plane movements are not inhibited. Likewise, boundary conditions, load pattern and cross sections dimensions have influence on the critical moment. In Fig. 1, a fork supported doubly symmetric I shaped steel beam is subjected to uniform moment $M_{o}$ with respect to its major bending axis and differential equation for LTB is given with Eq. (7)v[7].

$$
E C_{w} \frac{d^{4} \varnothing}{d z^{4}}-G J \frac{d^{2} \varnothing}{d z^{2}}-\frac{M_{0}^{2} \varnothing}{E I_{y}}=0,
$$

where: $E$ is the modulus of elasticity, $C_{w}$ is the warping constant, $G$ is the shear modulus, $J$ is the torsional constant, $I_{y}$ is the moment of inertia with respect to the weak axis, and $\varnothing$ is the twisting angle.

Nominal flexural strength according to the limit state of elastic LTB for a uniform bending moment diagram along the unbraced length can be written as Eq. (8) [7]. In the derivation of Eq. (8), lateral deflection and twisting are prevented at the both ends of the beam whereas beam ends are free to rotate laterally and free to wrap.

$$
M_{\text {ocr }}=\frac{\pi}{L} \sqrt{E I_{y} G J+\left(\frac{\pi E}{L}\right)^{2} I_{y} C_{w}} .
$$

Since closed-form solutions cannot be derived for most of the structural cases of LTB, numerical methods are widely used in calculations [20]. Consequently, the results are generally presented in the form of charts, tables, and special-purpose approximate expressions [22, 23]. For this reason, a numerical method based on finite difference approach is used in the study.

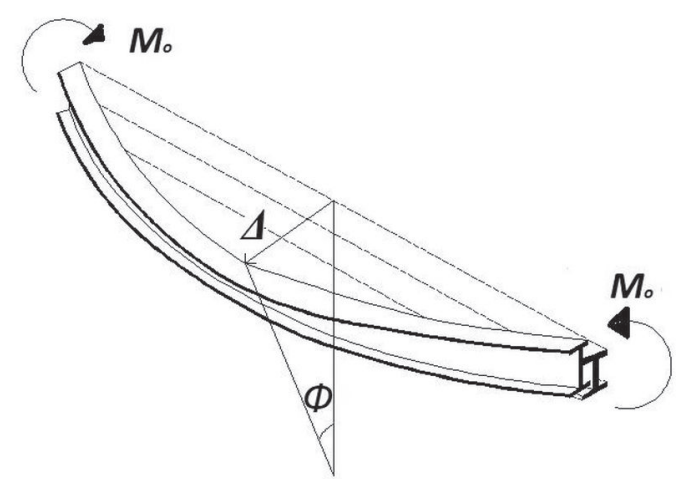

Fig. 1 Lateral torsional buckling of doubly symmetric $I$ shaped member under uniform moment $M_{\circ}$

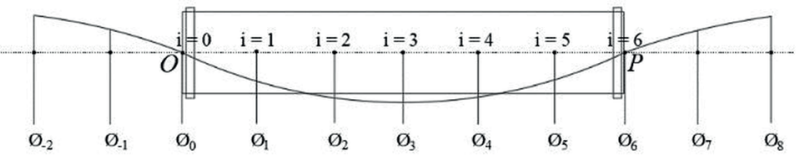

Fig. 2 Example of grid points in finite difference approximation

\subsection{Lateral torsional buckling analysis using finite difference approach}

In order to calculate LTB, fourth order differential equation is solved using finite difference approach. In this study, first term of Taylor series of each derivative is used. In order to obtain numerical solution of $\varnothing$, member is divided into equally spaced grid points. At a point $z=z_{i}$, the first to fourth derivatives of $\varnothing(z)$ can be written as Eqs. (9-12).

$$
\begin{aligned}
& \varnothing_{i}^{\prime}=\frac{1}{2 \Delta z}\left(-\varnothing_{i-1}+\varnothing_{i+1}\right), \\
& \varnothing_{i}^{\prime \prime}=\frac{1}{\Delta z^{2}}\left(\varnothing_{i-1}-2 \varnothing_{i}+\varnothing_{i+1}\right), \\
& \varnothing_{i}^{\prime \prime \prime}=\frac{1}{2 \Delta z^{3}}\left(-\varnothing_{i-2}+3 \varnothing_{i-1}-3 \varnothing_{i+1}+\varnothing_{i+2}\right), \\
& \varnothing_{i}^{\prime \prime \prime}=\frac{1}{\Delta z^{4}}\left(\varnothing_{i-2}-4 \varnothing_{i-1}+6 \varnothing_{i}-4 \varnothing_{i+1}+\varnothing_{i+2}\right) .
\end{aligned}
$$

Finite difference representation at a grid point for fourth order differential equation contains five function values. Therefore, the use of Eqs. (9-12) at a beam end, which is shown as grid point $\mathrm{O}$ in Fig. 2, requires two extra function values, namely $\varnothing_{-1}$ and $\varnothing_{-2}$. Two equations at point $\mathrm{O}$ are required in order to represent boundary conditions at that point. If a member is divided into $\mathrm{m}$ segments, then the use of finite difference methods requires four additional function values. There are $(m+1)$ finite difference equations for $(m+5)$ unknowns, so that four boundary conditions are needed. At each end, two boundary conditions are required, one condition involves torsion, and the other one involves warping.

Finite difference representation of differential equation at any arbitrary point $i$. becomes as Eq. (14) if three constants determined with Eq. (13) are used.

$$
\begin{aligned}
& a=\frac{E C_{w}}{\Delta z^{4}} \quad b=-\frac{G J}{\Delta z^{2}} c=-\frac{M_{0}^{2}}{E I_{y}}, \\
& a\left(\varnothing_{i-2}-4 \varnothing_{i-1}+6 \varnothing_{i}-4 \varnothing_{i+1}+\varnothing_{i+2}\right) \\
& +b\left(\varnothing_{i-1}-2 \varnothing_{i}+\varnothing_{i+1}\right)+c \varnothing_{i=0} .
\end{aligned}
$$

If one assumes the beam is divided into, for instance ten segments, Eq. (14) is then evaluated at grid points $i=0,1,2, \ldots, 10$, so there are eleven equations. The 
boundary conditions at the two ends are given with Eq. (15) and Eq. (16). Eleven finite difference representation at the grid points and two additional boundary conditions at each end make a linear simultaneous equation system of the size of fifteen.

$$
\begin{aligned}
& \varnothing=\left.0\right|_{z=0, z=L}, \\
& \frac{d^{2} \varnothing}{d z^{2}}=\left.0\right|_{z=0, z=L} .
\end{aligned}
$$

In the finite difference approach, Eq. (15) and Eq. (16) can be written in the form as in Eq. (17).

\begin{tabular}{l|r}
$\varnothing_{i}=0$ & at $z=0 \rightarrow i=0$ \\
$\varnothing_{i-1}-2 \varnothing_{i}+\varnothing_{i+1}=0$ & $z=L \rightarrow i=m$
\end{tabular}.

In this study, a member that is subjected to vertical uniformly distributed load and unequal end moments is focused as shown in Fig. 3 and finite difference approach is applied accordingly.

Unequal end moment values are defined as $\beta_{1} q L^{2} / 12$ at one end and $\beta_{2} q L^{2} / 12$ at the other end. The bending moment equation for this case is shown with Eq. (18).

$$
\begin{aligned}
& \mathrm{M}_{0}=-\mathrm{qz}^{2} / 2 \\
& +\left[\mathrm{qz}^{2} / 2+\left(\beta_{1} \mathrm{qz}^{2} / 12-\beta_{2} \mathrm{qz}^{2} / 12\right) / \mathrm{L}\right] \mathrm{z}-\beta_{1} \mathrm{qz}^{2} / 12,
\end{aligned}
$$

where $z$ is measured from the beam end where the moment $M$ acts. For finite difference approach, Eq. (18) can be written as Eq. (19).

$$
\begin{aligned}
& M_{0}=q / 2 \\
& {\left[-(i / L . \Delta z)^{2}+L+L / 6\left(\beta_{1}-\beta_{2}\right) i / L . \Delta z-\beta_{1} q L^{2} / 6\right],}
\end{aligned}
$$

where $z=I \cdot \Delta z$. By substituting moment $M_{0}$ in Eq. (19) into Eq. (7), the differential equation that is used in the finite difference approach for this load case becomes as Eq. (20).

$$
\begin{aligned}
& E C_{w} \frac{d^{4} \varnothing}{d z^{4}}-G J \frac{d^{2} \varnothing}{d z^{2}} \\
& -\frac{q^{2}}{4 E I_{y}}\left[-\left(\frac{i}{L} . \Delta z\right)^{2}+L+\frac{L}{6}\left(\beta_{1}-\beta_{2}\right) \frac{i}{L} . \Delta z-\beta_{1} \frac{q L^{2}}{6}\right]^{2} \varnothing=0 .
\end{aligned}
$$

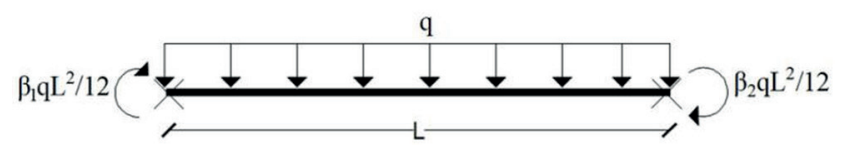

Fig. 3 Member subjected to uniformly distributed load and unequal end moments
Finite difference method is used for solving the differential equation in Eq. (12) considering boundary conditions using Matlab [23] in this study.

\subsection{Lateral torsional buckling calculation according to AISC 360-16}

LTB analysis can be performed by many internationally accepted standards and codes and one of the popular and practical one is AISC 360-16 [13]. For doubly symmetric I shape cross-section elements exposed to the bending moment on the strong axis, Mn can be calculated using Eqs. (21-23)

$M_{n}=M_{p}=F_{y} Z_{x}$,

$M_{n}=C_{b}\left[M_{p}-\left(M_{p}-0.7 F_{y} S_{x}\right) \frac{\left(L_{b}-L_{p}\right)}{\left(L_{r}-L_{p}\right)}\right] \leq M_{p}$,

$M_{n}=\frac{C_{b} \pi^{2} E}{\left(L_{b} / r_{t s}\right)} \sqrt{1+0.078 J c\left(S_{x} h_{o}\right)\left(\frac{L_{b}}{r_{t s}}\right)^{2}} S_{x} \leq M_{p}$,

where: $S_{x}$ and $Z_{x}$ are the elastic section modulus and the plastic section modulus about the strong axis, $L_{b}$ is the length of the unbraced segment of member, $L_{p}$ and $L_{r}$ are length limits defined in AISC 360-16 [13], $F_{y}$ is the specified yield stress of the steel, $h_{o}$ is the distance between the flange centroids. $C_{b}$ is the LTB modification factor for non-uniform moment diagrams and $r_{t s}$ is determined in Eq. (24).

$r_{t s}^{2}=\sqrt{I_{y} C_{w}} / S_{x}$.

The shapes of the bending moment diagrams for LTB are taken into account by multiplying by the moment modification factor $C_{b}$ which is presented in Eq. (25). In cases where the moment diagrams can be expressed to specific geometric shapes, it is possible to calculate the moment modification factor in practice for determining the LTB behavior. Moreover, some design specifications [18] allow to account moment modification factor, $C_{b}$ as 1 conservatively without performing Eq. (25).

In order to improve the capability of representing LTB behavior precisely, some studies are performed about accuracy of moment modification factor. Serna et al. [21] which is strongly dependent on both the bending moment distribution and restrictions at end supports. This paper focuses on the equivalent uniform moment factor (EUMF provide an equation for moment modification factor by using finite element techniques and it is given in Eq. (26). 
Likewise, Wong and Driver [22] proposed an equation using improved quarter-point formula for $C_{b}$ factor and it is presented in Eq. (27). These approaches are significant contributions to the literature [20] and they are also used for comparison in the numerical analysis carried out as the part of this study.

$$
\begin{aligned}
& C_{b}=12.5 M_{\text {max }} /\left(2.5 M_{\text {max }}+3 M_{A}+4 M_{B}+3 M_{C}\right), \\
& C_{b}=\sqrt{35 M_{\text {max }}^{2} /\left(M_{\text {max }}^{2}+9 M_{A}^{2}+16 M_{B}^{2}+9 M_{C}^{2}\right.}, \\
& C_{b}=4 M_{\text {max }} / \sqrt{M_{\text {max }}^{2}+4 M_{A}^{2}+7 M_{B}^{2}+4 M_{C}^{2}} \leq 2.5,
\end{aligned}
$$

where: $M_{\max }$ is the maximum moment, and $M_{A}, M_{B}$ and $M_{C}$ are the values for the moment at $0.25,0.50$ and 0.75 of the unbraced lengths of the member, respectively.

\section{Implementation of Lateral Torsional Buckling behavior in Inelastic Ultimate Load Analysis of steel frame}

The conventional inelastic ultimate load analyses, however, do not consider the degradation of the flexural strength and stiffness caused by the LTB, assuming the lateral torsional motion to be prevented by adequate lateral bracings. The analysis should be improved to consider LTB, since the real structures are not always provided with sufficient lateral supports. For this reason, a numerical method is proposed for determining inelastic ultimate load capacity of steel frames considering LTB behavior under uniformly distributed loads. In the analyses, inelastic material behavior, second-order effects and residual stresses of the structural frame system and its members are accounted for the approach used in the study. The proposed method is given in details with a flow chart as shown in Fig. 4.

\section{Numerical examples}

Steel plane frame structures are selected from literature $[16,24,25]$ in order to validate the proposed method and show the importance of LTB effect on the capacity and behavior of steel frames. Geometric properties, member sections and loads that act on the steel frames are given in the relevant figures. In all examples, laterally unbraced lengths are accounted as same as the beam lengths. In the inelastic ultimate load analysis of steel frames under distributed loads, second-order effects, plastic hinges and residual stress effects are considered according to the equations presented in AISC 360-16 [13].
In the inelastic ultimate load analysis steps, LTB is precisely considered with the proposed method and results are compared with solutions considering Serna et al. [21] Eq. (26), Wong and Driver [22] Eq. (27) and AISC 36016 [13] design specification Eq. (25). In the numerical analysis using proposed method calculations steps provided by work flow chart given in Fig. 4 are followed, members are divided into 300 equal length elements considering the accuracy of the results.

\subsection{One-story and one-bay steel frame}

One-story and one-bay steel frame is selected from the literature [16, 25] and it's geometric properties and loading are presented in Fig. 5. Horizontal displacement at the top of the steel frame is marked as $\Delta$.

Critical moment values for the beam member of the frame, considering LTB behavior for various end moments are calculated and results are shown in Fig. 6.

Inelastic ultimate load analysis of one-story and onebay steel frame with uniformly distributed load applied is performed and load parameter and horizontal displacement at the top of the steel frame are calculated with and without considering LTB effect. Analysis results are presented in Fig. 7, comparatively.

Ultimate load capacity and horizontal displacement at the top of the steel frame under uniformly distributed load considering LTB is calculated with the proposed method and the other methods based on AISC 360-16 [13] and equations from the literature. Ultimate values for load carrying capacity and lateral displacement of steel frame are presented in Table 1. LTB decreases the load carrying and displacement capacity of the steel frame for all methods considered in the study. Moreover, assuming moment modification factor as $C_{b}=1$ caused relatively conservative results.

Table 1 Ultimate load factor and displacement results for one-story and one-bay frame

\begin{tabular}{lcc}
\hline Type of Analysis & $\begin{array}{c}\text { Ultimate load } \\
\text { factor }\end{array}$ & $\begin{array}{c}\text { Displacement } \\
(\mathrm{mm})\end{array}$ \\
\hline $\begin{array}{l}\text { LTB neglected } \\
\text { LTB considering the Eq. (26) of } \\
\text { Serna et al. }\end{array}$ & 0.921 & 112.7 \\
$\begin{array}{l}\text { LTB considering proposed method } \\
\text { LTB considering the Eq. (27) of } \\
\text { Wong and Driver }\end{array}$ & 0.916 & 82.2 \\
$\begin{array}{l}\text { LTB considering AISC 360-16 } \\
\begin{array}{l}\text { LTB considering AISC 360-16 } \\
\text { with assuming } C_{b}=1\end{array}\end{array}$ & 0.894 & 81.2 \\
\hline
\end{tabular}




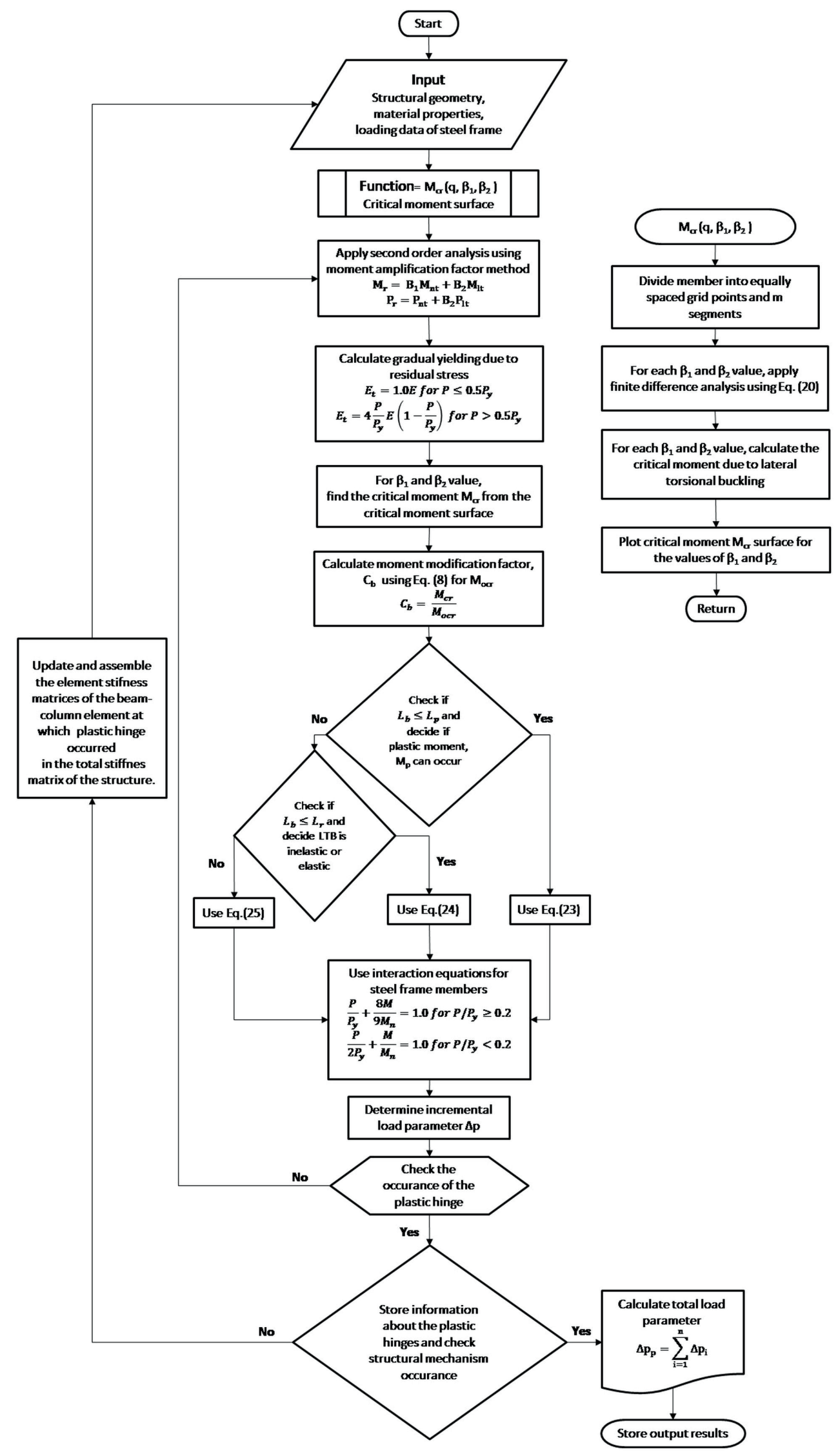

Fig. 4 Flow chart for inelastic ultimate load analysis considering lateral torsional buckling 


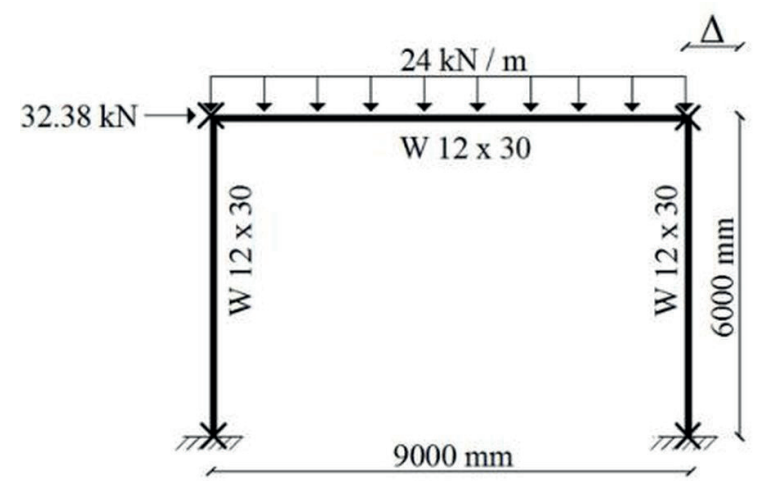

Fig. 5 One-story and one-bay steel frame

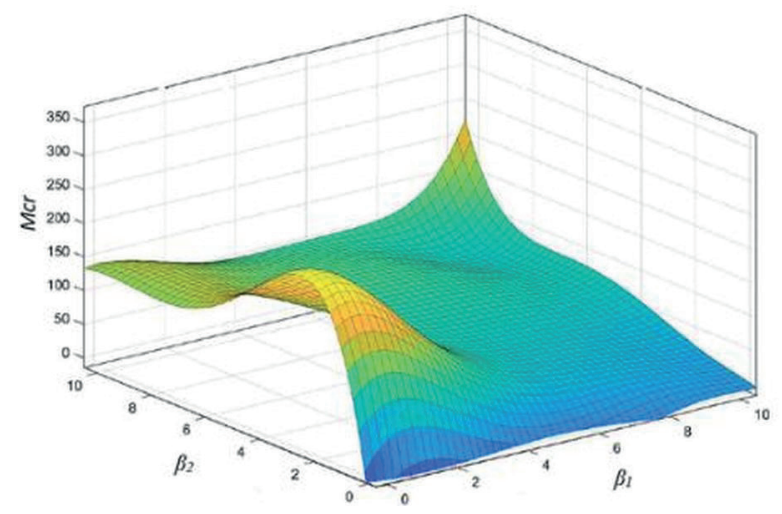

Fig. 6 Critical moment values of W12 $\times 30$ for $\beta_{1}$ and $\beta_{2}$ values

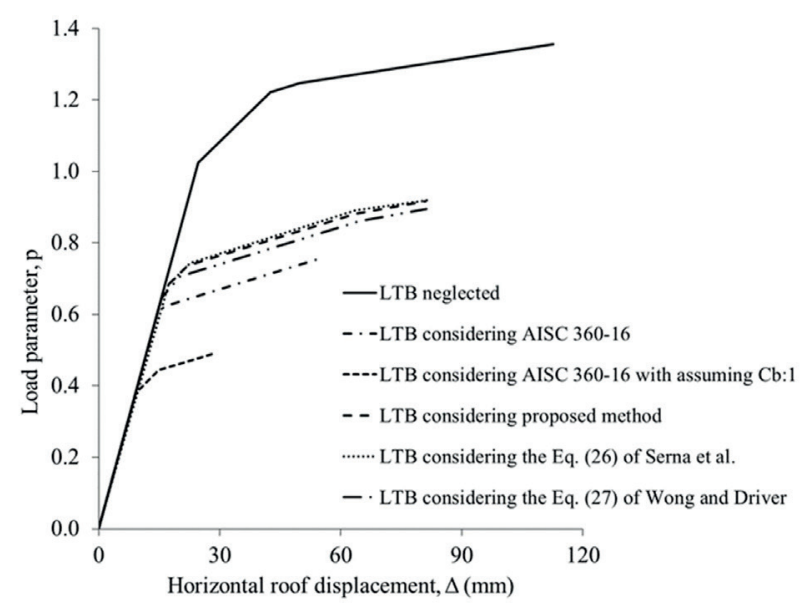

Fig. 7 One-story and one-bay steel frame analysis results

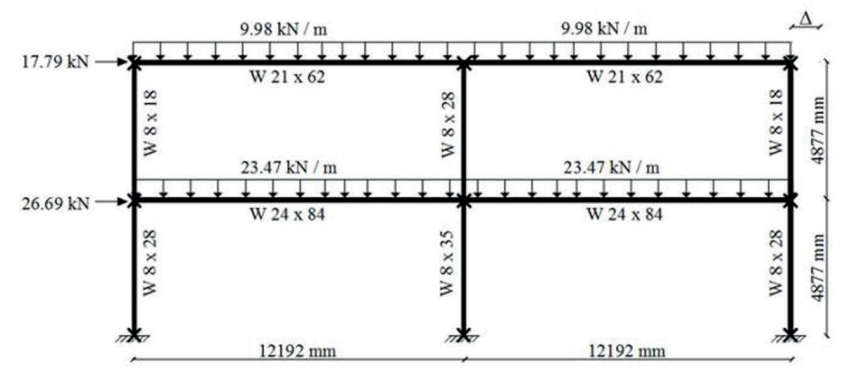

Fig. 8 Two-story and two-bay steel frame

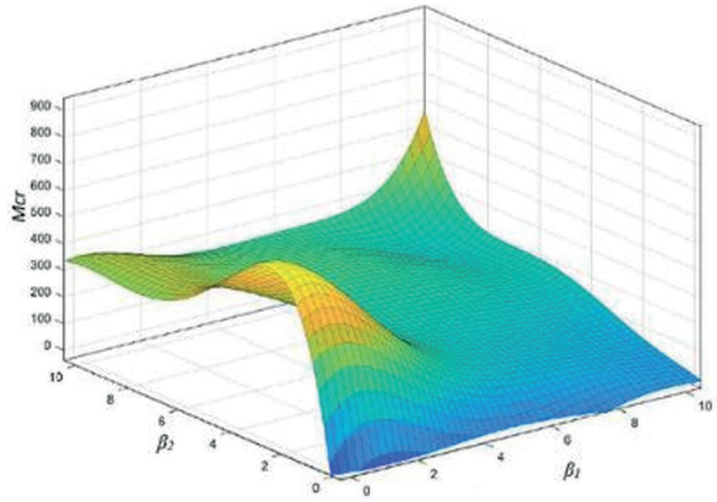

(a)

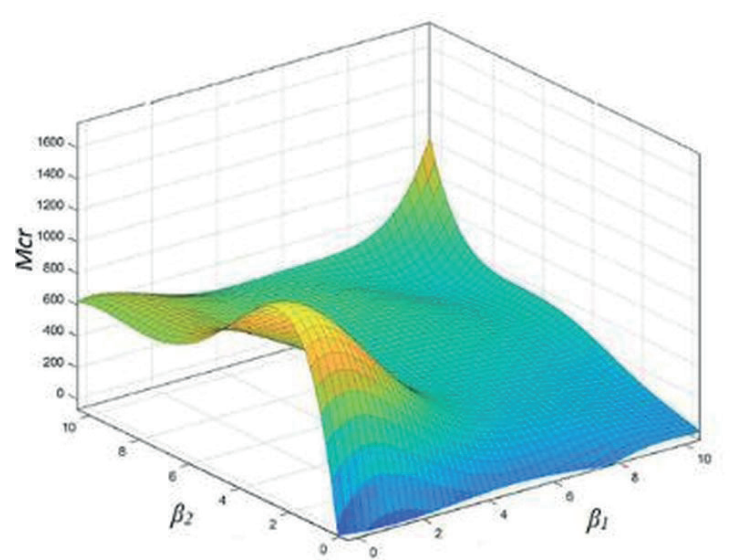

(b)

Fig. 9 Critical moment values of (a) W21 $\times 62$ (b) W24 $\times 84$ for $\beta_{1}$ and $\beta_{2}$ values

\subsection{Two-story and two-bay steel frame}

A steel frame with two-story and two-bay is selected from the literature $[24,25]$ and it's geometric properties and loading are presented in Fig. 8. Horizontal displacement at the top of the steel frame is shown as $\Delta$.

Critical moment values for the beam members of the frame considering LTB behavior for various end moments are calculated and results are shown in Fig. 9.

Inelastic ultimate load analysis of the steel frame is performed and the relationship between the load parameter and horizontal displacement at the top of the steel frame is presented in Fig. 10 with and without considering LTB effect. At first, inelastic ultimate load analysis of steel frame results of this study and the reference study [24] is compared and $0.8 \%$ difference is observed for ultimate load parameters in the case when LTB is neglected.

Ultimate load carrying capacity and lateral displacement of steel frame decreased significantly, as LTB is encountered in the analysis as presented in Table 2. Since ultimate load carrying capacity calculations are dependent on the moment modification factor equations, analysis results 
Table 2 Ultimate load factor and displacement results for two-story and two-bay frame

\begin{tabular}{lcc}
\hline Type of Analysis & $\begin{array}{c}\text { Ultimate load } \\
\text { factor }\end{array}$ & $\begin{array}{c}\text { Displacement } \\
(\mathrm{mm})\end{array}$ \\
\hline $\begin{array}{l}\text { Foley and Vinnakota [24] (LTB } \\
\text { neglected) }\end{array}$ & 1.911 & 104.6 \\
$\begin{array}{l}\text { LTB neglected } \\
\begin{array}{l}\text { LTB considering the Eq. (26) of } \\
\text { Serna et al. }\end{array}\end{array}$ & 1.896 & 102.2 \\
$\begin{array}{l}\text { LTB considering proposed method } \\
\text { LTB considering the Eq. (27) of }\end{array}$ & 1.717 & 70.6 \\
$\begin{array}{l}\text { Wong and Driver } \\
\text { LTB considering AISC 360-16 }\end{array}$ & 1.687 & 71.1 \\
$\begin{array}{l}\text { LTB considering AISC 360-16 with } \\
\text { assuming } C_{b}=1\end{array}$ & 1.133 & 66.1 \\
\hline
\end{tabular}

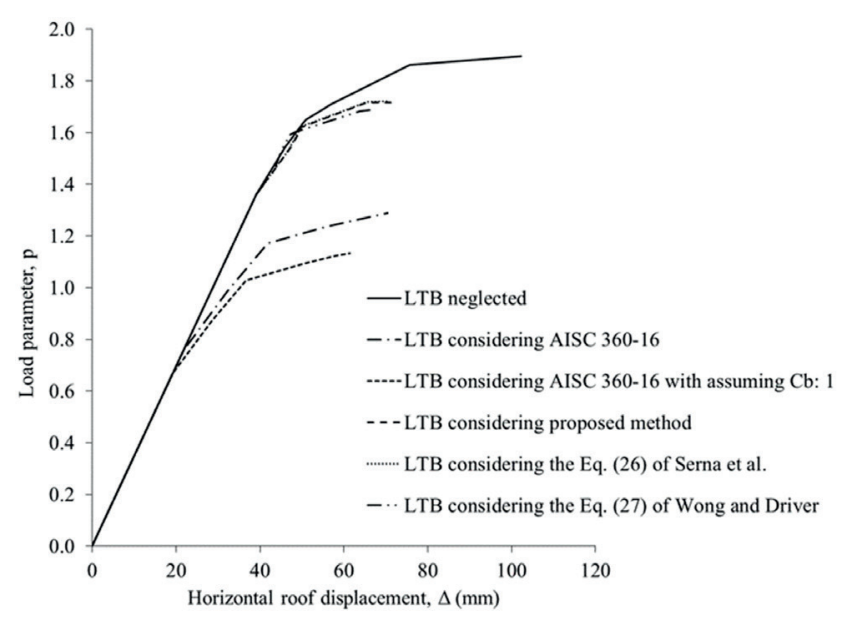

Fig. 10 Two-story and two-bay steel frame analysis results

using Serna et al. [21] Eq. (26), Wong and Driver [22] Eq. (27) and the proposed method are different from the results of AISC 360-16 [13] design specification Eq. (25). This is due to a fact that, moment modification factor of AISC 360-16 [13] is aimed to be used for general load cases; its results are relatively conservative for steel frame subjected to uniformly distributed load.

\subsection{Three-story and two-bay steel frame}

A steel frame with three-story and two-bay is selected from the literature [24, 25] and it is shown in Fig. 11. Horizontal displacement at the top of the steel frame is marked as $\Delta$.

Critical moment values for the beam members of the frame considering LTB behavior for various end moments are calculated and results are shown in Fig. 12.

Inelastic ultimate load analysis of three-story and twobay steel frame is performed and load parameter and horizontal displacement at the top of the steel frame are determined with and without considering LTB effect as shown in Fig. 13. Inelastic ultimate load analysis of steel frame results show that the difference in ultimate load carrying capacity of this study and the reference study [24] is $1.2 \%$ considering the case when LTB is neglected.

Ultimate load carrying capacity and lateral displacements of steel frames decreased due to considering LTB behavior and analysis results are shown in Table 3.

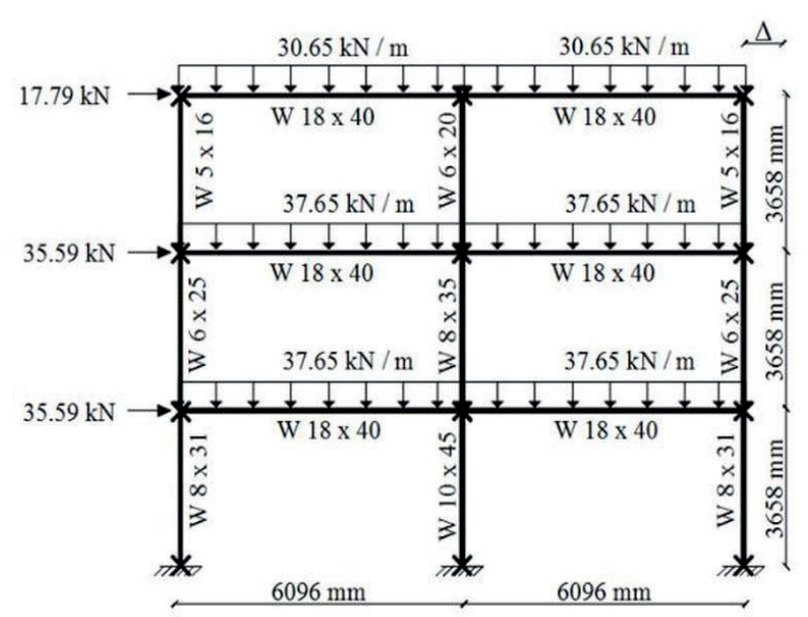

Fig. 11 Three-story and two-bay steel frame

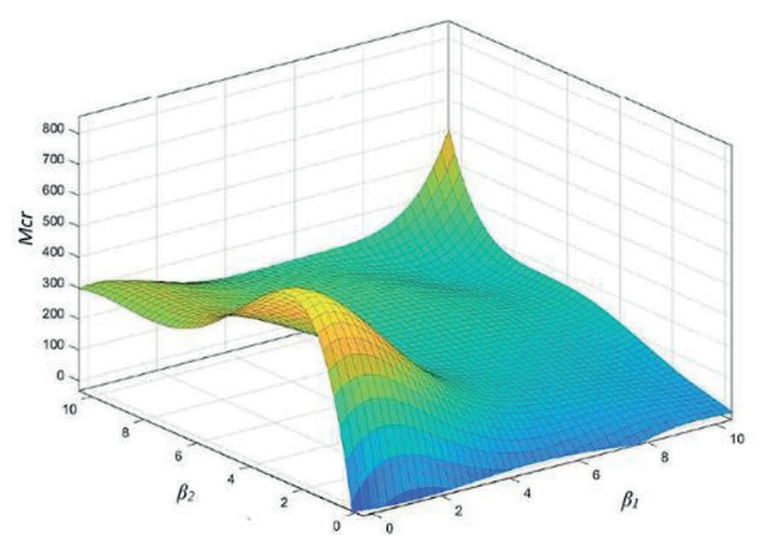

Fig. 12 Critical moment values of W $18 \times 40$ for $\beta_{1}$ and $\beta_{2}$ values

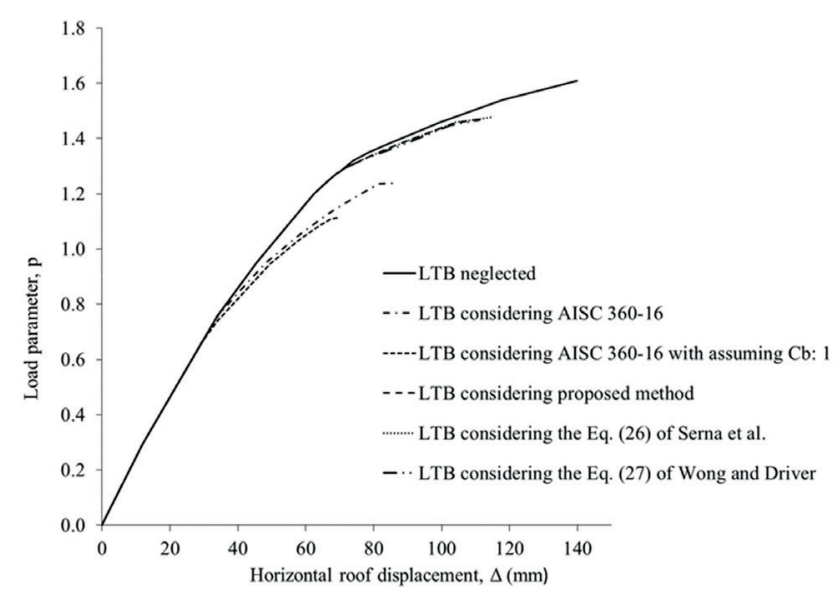

Fig. 13 Three-story and two-bay steel frame analysis results 
Table 3 Ultimate load factor and displacement results for three-story and two-bay frame

\begin{tabular}{lcc}
\hline Type of Analysis & $\begin{array}{c}\text { Ultimate } \\
\text { load factor }\end{array}$ & $\begin{array}{c}\text { Displacement } \\
(\mathrm{mm})\end{array}$ \\
\hline $\begin{array}{l}\text { Foley and Vinnakato [24](LTB } \\
\text { neglected) }\end{array}$ & 1.632 & 140.2 \\
$\begin{array}{l}\text { LTB neglected } \\
\text { LTB considering the Eq. (26) of }\end{array}$ & 1.612 & 139.9 \\
$\begin{array}{l}\text { Serna et al. } \\
\text { LTB considering proposed method }\end{array}$ & 1.473 & 115.3 \\
$\begin{array}{l}\text { LTB considering the Eq. (27) of } \\
\text { Wong and Driver }\end{array}$ & 1.467 & 111.5 \\
$\begin{array}{l}\text { LTB considering AISC 360-16 } \\
\text { LTB considering AISC 360-16 with } \\
\text { assuming } C_{b}=1\end{array}$ & 1.237 & 86.0 \\
\hline
\end{tabular}

Analysis results using moment modification factor equations of Serna et al. [21] Eq. (26), Wong and Driver [22] Eq. (27) and the proposed method show relatively close results with each other.

\section{Conclusions}

In this study, a method that considers LTB in the load increment steps of the inelastic ultimate load analysis of steel frames under distributed loads is proposed and numerical examples from the literature are considered for comparison of analysis results. Outcomes of this study are summarized as follows.

- Numerical examples considered in the study show that LTB directly affects the steel frame behavior and load carrying capacity. Therefore, it is a crucial issue for steel structures and it has to be considered in analysis and design stages.

\section{References}

[1] Grigorian, M., Grigorian, C. E. "Recent developments in plastic design analysis of steel moment frames", Journal of Constructional Steel Research, 76, pp. 83-92, 2012.

https://doi.org/10.1016/j.jcsr.2012.03.011

[2] Dehghani, E., Hamidi, S. A., Tehrani, F. M., Goyal, A., Mirghaderi, R. "New Practical Approach to Plastic Analysis of Steel Structures", Periodica Polytechnica Civil Engineering, 59(1), pp. 27-35, 2015. https://doi.org/10.3311/PPci.7578

[3] Jankowska-Sandberg, J., Kołodziej, J. "Experimental study of steel truss lateral-torsional buckling", Engineering Structures, 46, pp. 165-172, 2013.

https://doi.org/10.1016/j.engstruct.2012.07.033

[4] Valarinho, L., Correia, J. R., Machado-e-Costa, M., Branco, F. A., Silvestre, N. "Lateral-torsional buckling behaviour of long-span laminated glass beams: Analytical, experimental and numerical study", Materials \& Design, 102, pp. 264-275, 2016.

https://doi.org/10.1016/j.matdes.2016.04.016
- LTB analyses are generally focused by considering one-member solutions or only at a beam-member element level. This study shows the influence of LTB on the ultimate load capacity of steel frames and the whole structural behavior is presented numerically, using proposed and some recent approaches.

- Inelastic ultimate load analyses of steel frames under uniformly distributed loads considering LTB are performed by using the proposed method, AISC 360-16 design specification equations and approaches from the literature. Analysis results show that, the proposed method gives sufficient outcomes when it is compared with the moment modification factor approaches used from the literature and AISC 360-16 design specification equations. Therefore, the proposed analysis method is shown to be an efficient and consistent tool.

- Most of the equations for LTB calculations consider moment modification factor using four points of the moment diagram. This ensures that the shape of the moment diagram is reflected in LTB calculations. Alternatively, this study uses only beam end moments and the distributed loading value of the members to calculate critical moment for LTB behavior. This advantage can be applied to steel frames subjected to uniformly distributed load, which is a widely used load case in structural engineering problems.

- Analysis results show that when moment modification factor $C_{b}$ is accounted as 1 , analysis results become conservative if economical designs are targeted. For this reason, moment modification factors should be precisely calculated in all steps of the numerical analysis.

[5] Kala, Z. "Sensitivity and reliability analyses of lateral-torsional buckling resistance of steel beams", Archives of Civil and Mechanical Engineering, 15(4), pp. 1098-1107, 2015. https://doi.org/10.1016/j.acme.2015.03.007

[6] Sonck, D., Belis, J. "Lateral-torsional buckling resistance of cellular beams", Journal of Constructional Steel Research, 105, pp. 119-128, 2015.

https://doi.org/10.1016/j.jcsr.2014.11.003

[7] Timoshenko, S. P., Gere, J. M. "Theory of elastic stability", 2nd ed., McGraw-Hill, Auckland, New-Zealand, 1963.

[8] Galambos, T. V. "Structural members and frames", 1st ed., PrenticeHall, Upper Saddle River, NJ, USA, 1968.

[9] Brown, P.T., Trahair, N. "Finite integral solution of differential equations", Civil Engineering Transactions, Institute of Engineers, CE10, pp. 193-196, 1968.

[10] McGuire, W., Gallagher, R. H., Ziemian, R. D. "Matrix structural analysis", 2nd ed., Wiley, New York, NY, USA, 1999. 
[11] Suryoatmono, B., Ho, D. "The moment-gradient factor in lateral-torsional buckling on wide flange steel sections", Journal of Constructional Steel Research, 58(9), pp. 1247-1264, 2002. https://doi.org/10.1016/S0143-974X(01)00061-X

[12] Ziemian, R. D., Miller, A. R. "Inelastic Analysis and Design: Frames with Members in Minor-Axis Bending", Journal of Structures Engineering, 123(2), pp. 151-156, 1997. https://doi.org/10.1061/(ASCE)0733-9445(1997)123:2(151)

[13] AISC "ANSI/AISC 360-16 Specification for Structural Steel Buildings", American Institute of Steel Construction, Chicago, IL, USA, 2016, [online] Available at: https:/www.aisc.org/globalassets/aisc/publications/standards/a360-16-spec-and-commentary.pdf [Accessed: 05 July 2019]

[14] Rigobello, R., Coda, H. B., Neto, J. M. "Inelastic analysis of steel frames with a solid-like finite element", Journal of Constructional Steel Research, 86, pp. 140-152, 2013.

https://doi.org/10.1016/j.jcsr.2013.03.023

[15] Wang, W., Clausen, P. M., Bletzinger, K.-U. "Improved semi-analytical sensitivity analysis using a secant stiffness matrix for geometric nonlinear shape optimization", Computer \& Structures, 146, pp. 143-151, 2015.

https://doi.org/10.1016/j.compstruc.2014.08.008

[16] Al-Mashary, F., Chen, W. F. "Elastic second-order analysis for frame design", Journal of Constructional Steel Research, 15(4), pp. 303322, 1990.

https://doi.org/10.1016/0143-974X(90)90052-I

[17] Thai, H.-T., Kim, S.-E. "Practical advanced analysis software for nonlinear inelastic analysis of space steel structures", Advances in Engineering Software, 40(9), pp. 786-797, 2009. https://doi.org/10.1016/j.advengsoft.2009.02.001
[18] TSDC-2018 "Turkish Steel Design Code", Principles of Design, Calculation and Construction of Steel Structures, Ministry of Environment and Urbanization, Ankara, Turkey, 2018. (in Turkish) [online] Available at: http://www.resmigazete.gov.tr/eskiler/2018/02/20180215M1-4-1.pdf [Accessed: 05 July 2019]

[19] Agüero, A., Pallarés, F. J., Pallarés, L. "Equivalent geometric imperfection definition in steel structures sensitive to lateral torsional buckling due to bending moment", Engineering Structures, 96, pp. 41-55, 2015.

https://doi.org/10.1016/j.engstruct.2015.03.066

[20] Ziemian, R. D. "Guide to Stability Design Criteria for Metal Structures", 6th ed., John Wiley \& Sons Inc., Hoboken, New Jersey, USA, 2010 https://doi.org/10.1002/9780470549087.fmatter

[21] Serna, M. A., López, A., Puente, I., Yong, D. J. "Equivalent uniform moment factors for lateral-torsional buckling of steel members", Journal of Constructional Steel Research, 62(6), pp. 566-580, 2006. https://doi.org/10.1016/j.jcsr.2005.09.001

[22] Wong, E., Driver, R. G. "Critical Evaluation of Equivalent Moment Factor Procedures for Laterally Unsupported Beams", ASCI Engineering Journal, 47, pp. 1-20, 2010. [online] Available at: https://www.aisc.org/.XVQV7OP7RaR [Accessed: 05 July 2019]

[23] MathWorks "Matlab R2013a", [computer program] Available at: https://www.mathworks.com/videos/discover-matlab-r2013a-92904. html?s_tid=srchtitle [Accessed: 05 July 2019]

[24] Foley, C. M., Vinnakota, S. "Inelastic analysis of partially restrained unbraced steel flames", Engineering Structures, 19(11), pp. 891$902,1997$. https://doi.org/10.1016/S0141-0296(97)00175-2

[25] Uzun, E. T. "Nonlinear Analysis of Steel Frames Considering Lateral Torsional Buckling", MSc Thesis, Izmir Katip Celebi University, 2017. 